\title{
Geospatial Analysis of Urban Expansion Using Remote Sensing Methods and Data: A Case Study of Yangtze River Delta, China
}

\author{
Wei Sun $\mathbb{D D}^{1,2}$ Jie Shan, ${ }^{3}$ Zhiming Wang, ${ }^{3}$ Lei Wang, ${ }^{1,4}$ Dianmei Lu, ${ }^{5}$ Zhifeng Jin, ${ }^{6,7}$ \\ and Kun Yu iD ${ }^{3}$ \\ ${ }^{1}$ Nanjing Institute of Geography \& Limnology, Chinese Academy of Sciences, Nanjing, Jiangsu 210008, China \\ ${ }^{2}$ Key Laboratory of Watershed Geographic Sciences, Chinese Academy of Sciences, Nanjing, Jiangsu 210008, China \\ ${ }^{3}$ Institute of Agricultural Information, Jiangsu Academy of Agricultural Sciences, Nanjing, Jiangsu 210014, China \\ ${ }^{4}$ Manchester Urban Institute, School of Environment, Education and Development, The University of Manchester, \\ Manchester M13 9PL, UK \\ ${ }^{5}$ Geological Exploration Technology Institute of Jiangsu Province, Nanjing, Jiangsu 210046, China \\ ${ }^{6}$ School of Resource and Environmental Sciences, Wuhan University, Wuhan, Hubei 430079, China \\ ${ }^{7}$ Jiangsu Research Center of Land and Resources, Nanjing, Jiangsu 210017, China
}

Correspondence should be addressed to Kun Yu; yukun@jaas.ac.cn

Received 9 June 2020; Revised 13 July 2020; Accepted 23 July 2020; Published 14 August 2020

Guest Editor: Jun Yang

Copyright $(2020$ Wei Sun et al. This is an open access article distributed under the Creative Commons Attribution License, which permits unrestricted use, distribution, and reproduction in any medium, provided the original work is properly cited.

\begin{abstract}
Land use in the Yangtze River Delta in 2000 and 2017 was classified by the visual interpretation of Landsat satellite images. Then, these images were overlain with economic and physical geographical data to analyze the urban spatial expansion pattern and its physical constraints and socioeconomic influence factors by employing a combination of transition matrix analysis, expansion intensity indices, and equal-fan analysis. The results showed that from 2000 to 2017, there was a significant increase in built-up areas in the region, with rapid expansion in the core area. The northern and southern parts of the Yangtze River Delta experienced different urban spatial expansions, with a higher scale and rate in the cities along the Yangtze River and the coast in Jiangsu Province in the north than in Zhejiang Province in the south. Cities expanded towards megacities or hubs along the Yangtze River or the coast, indicating that urban expansion is influenced by preferential policies and urban planning factors in addition to the spillover effects of neighboring cities and the adjacency to seas or large rivers. Finally, urban expansion is significantly constrained by elevation, with cities at lower elevations or in flat terrain undergoing more rapid urban expansion and development.
\end{abstract}

\section{Introduction}

Urbanization is a socioeconomic phenomenon with farreaching effects and is a major indicator of regional economic development and social progress. Following four decades of reform and opening-up to globalization, China has experienced rapid economic growth accompanied by rapid urbanization, with the urban population ratio increasing from $17.92 \%$ in 1978 to $59.58 \%$ in 2019 [1]. Urban land increased at an even higher rate, by nearly two and a half times, from the 1990s to early 2000s [2]. As such, urban spatial expansion is a major indicator of urbanization, making it necessary to implement long-term monitoring of urban expansion and in-depth studies of the rate, direction, and scale of expansion to identify the corresponding critical driving factors and reveal their variation patterns. In doing so, land resources can be analyzed in a systematic and reasonable manner to sufficiently balance urbanization and sustainable economic development.

Urbanization studies date back to the early 20th century, focusing on the spatiotemporal patterns, driving factors, and impact of urban expansion. A more theoretical system of urbanization research was established in the 1950s [3]. For example, based on an analysis of land consumption in Milan, Italy, Camagni et al. [4] identified the following modes of urban expansion: packing, extension, linear expansion 
(along transportation lines), sprawling, and "satellite" type expansion. Extensions of this research allowed for the inclusion of physical, socioeconomic, accessibility, and neighborhood factors in the analysis of urban expansion and the spatiotemporal variation of relevant driving factors [5]. Moreover, new emerging technologies and method$\mathrm{s}$-in particular, wide application of remote sensing technologies-have enabled urban expansion research on an immense spatiotemporal scale. Since the 1970s, the United States began to use long time series remote sensing data from Landsat to investigate the patterns and driving forces of urban land cover expansion and landscape metrics to predict future urban development trends $[6,7]$. Other countries are also currently focusing on monitoring and predicting the rapid urbanization of cities by using Landsat Thematic Mapper (TM) or Operational Land Imager (OLI) [8-11].

In recent years, with the increasing availability of remote sensing data, investigating urban development patterns through the integration of different sources of remote sensing information has become a popular avenue of urbanization research. For example, studies of the intensity and mode of construction land expansion in developed and developing countries using multiple-source remote sensing data and the Defense Meteorological Satellites Program/ Operational Linescan System (DMSP/OLS) night-time light data revealed the effect of policy factors at different economic development levels and of heterogeneous regional landscapes on urbanization [12-14]. Following the implementation of the Chinese national policy of reform and opening-up in the 1980s, the spatiotemporal changes of Chinese cities and their driving factors have attracted increasing attention from researchers [15-19].

In studies of the spatiotemporal differentiation and transfer patterns of urban land expansion of large and medium cities, including Shanghai, Beijing, Hangzhou, and Nanjing, remote sensing technology provided timely, costefficient, and effective data for large-scale urbanization research [20-25]. As a byproduct of investing increasing efforts for reform and economic accessibility, China experienced increasingly rapid urbanization. In particular, the Yangtze River Delta region is now considered the largest regional economy of China. In a regional development plan published by the Chinese government, the Yangtze River Delta is positioned as an economic center with the strongest comprehensive power in China; it is considered not only as a major international gateway to the Asia-Pacific region, but also as a major base of global advanced manufacturing and the first megalopolis of China with international implications. As such, urbanization in this region has become a popular research topic. However, most remote sensing databased studies of the urban spatiotemporal expansion in the Yangtze River Delta are outdated [26-30]. More recent studies of urbanization in this region have mainly focused on individual cities; however, a comprehensive investigation of the Yangtze River Delta is distinctly lacking. In this study, the Yangtze River Delta was investigated to establish the characteristics, patterns, and mechanisms of urban spatiotemporal expansion since 2000, in order to provide scientific input to urban development planning and sustainable economic development in the region.

\section{Materials and Methods}

2.1. Study Area. Located adjacent to the Yellow and East China Seas, the Yangtze River Delta megalopolis (Figure 1; $32^{\circ} 34^{\prime}-29^{\circ} 20^{\prime} \mathrm{N}, 115^{\circ} 46^{\prime}-123^{\circ} 25^{\prime} \mathrm{E}$ ) is comprised of two provinces as well as Shanghai municipality. The area has a subtropical monsoon climate and serves as a major interface of the Belt and Road economies and the Yangtze River economic belt. Covering an area of approximately $11 \times 10^{4} \mathrm{~km}^{2}$, the core of the megalopolis includes the cities of Shanghai, Nanjing, Yangzhou, Zhenjiang, Suzhou, Wuxi, Changzhou, Taizhou (Jiangsu), Nantong, Hangzhou, Shaoxing, Huzhou, Jiaxing, Ningbo, Zhoushan, and Taizhou (Zhejiang). This megalopolis is one of the most developed and urbanized regions in China and thus is both the most densely populated region in China and one of the six biggest megalopolises in the world [31]. In 2016, the region had a GDP of 1.8 trillion USD, accounting for $16.7 \%$ of the Chinese economy, with a population of more than $9800 \times 10^{4}[1,32,33]$.

\subsection{Data}

2.2.1. Satellite Data. TM and OLI are key instruments onboard Landsat satellites which have a ground revisit period of 16 days. In 2009, images collected by Landsat satellites became freely available from the United States Geological Survey (USGS), with historical images dating back to 1982 at $15 \sim 30 \mathrm{~m}$ pixel resolutions. A total of 7 spectral bands between $450 \mathrm{~nm}$ and $12.5 \mu \mathrm{m}$ and 9 spectral bands between $433 \mathrm{~nm}$ and $2.3 \mu \mathrm{m}$ are available by TM images and OLI images, respectively, allowing the exploration of the Earth's resources and environments on a global scale at maximal resolution but with minimal costs. Images from the Landsat series satellites were selected for this study, owing to the consistent resolution and continuity of the data. All data used in this study were provided by the USGS/EROS Data Center, including 16 views of images from the Landsat5 TM in 2000 and 15 views of images from the Landsat-8 OLI in 2017. All remote sensing images were of good quality and covered the entire study area (Table 1).

2.2.2. DEM Data. A digital elevation model (DEM) is a digital simulation of surface terrain using limited topographic elevation data (or a digital representation of the surface morphology) and is a physical model of surface elevation represented in matrices of ordered values. The Advanced Spaceborne Thermal Emission and Reflection Radiometer (ASTER) Global Digital Elevation Model (GDEM) V2 data used in this study were provided by the Geospatial Data Cloud (http://www.gscloud.cn). Compared with the ASTER GDEM V1 data, the V2 data use more advanced algorithms and have an enhanced spatial resolution and elevation accuracy. The V2 data have a spatial resolution of $30 \mathrm{~m}$ and are presented in the WGS84 


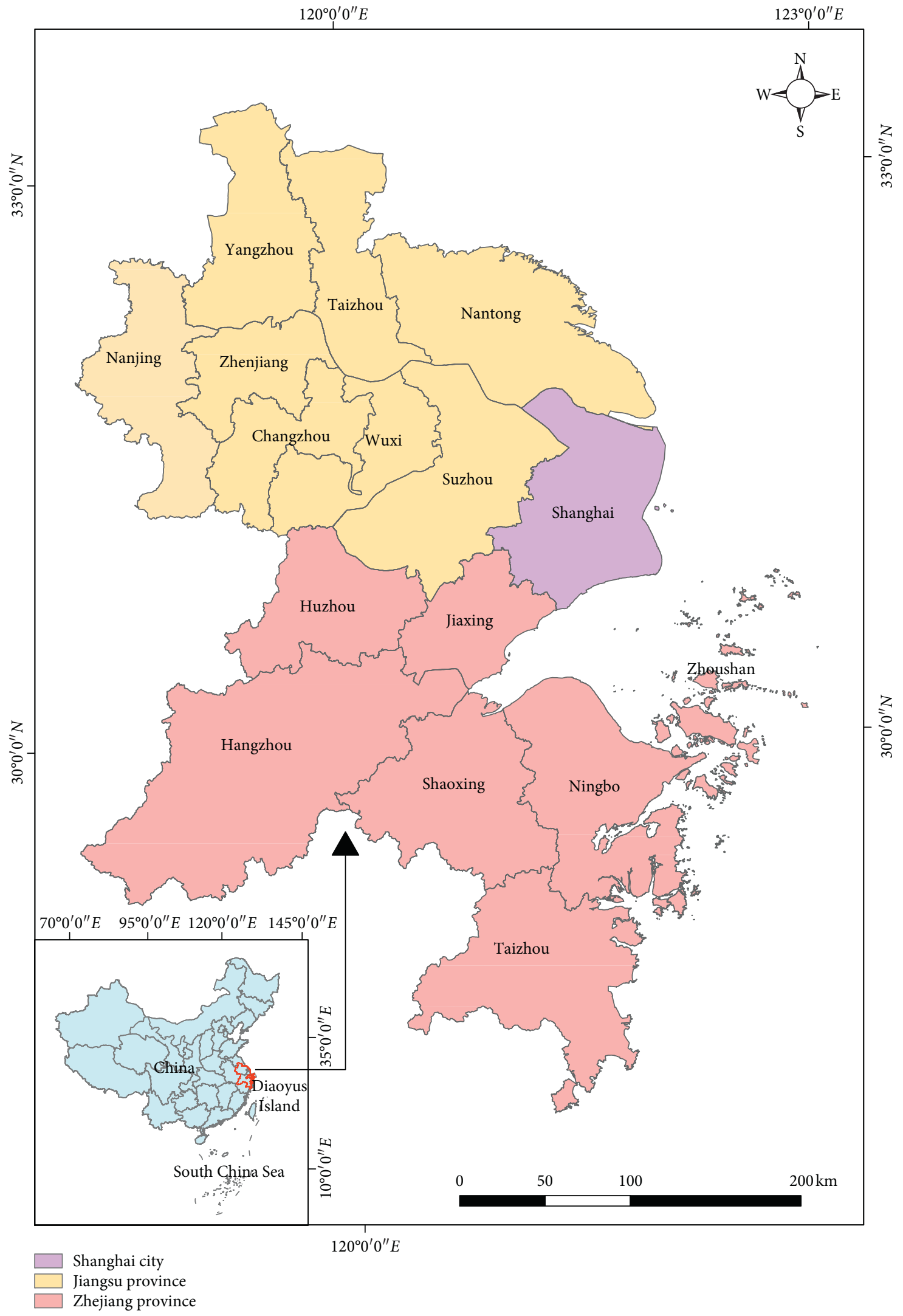

FIgURE 1: Yangtze River Delta megalopolis. Inset shows location within eastern China. 
TABLE 1: Landsat data used in this study.

\begin{tabular}{|c|c|c|c|}
\hline Collection date & Sensor & Orbit number & Ground resolution $(\mathrm{m})$ \\
\hline $2000 / 5 / 14$ & Landsat-5 TM & \multirow{3}{*}{117039} & 30 \\
\hline $2017 / 8 / 17$ & Landsat-8 OLI & & 15 \\
\hline $2000 / 5 / 21$ & Landsat-5 TM & & 30 \\
\hline $2017 / 4 / 2$ & Landsat-8 OLI & \multirow[t]{2}{*}{118038} & 15 \\
\hline $2017 / 8 / 24$ & & & \\
\hline $2000 / 6 / 6$ & Landsat-5 TM & \multirow{3}{*}{118039} & 30 \\
\hline $2017 / 4 / 2$ & Landsat-8 OLJ & & 15 \\
\hline $2017 / 8 / 24$ & Landsat-8 ULI & & 15 \\
\hline $\begin{array}{l}2000 / 2 / 15 \\
2000 / 7 / 24\end{array}$ & Landsat-5 TM & 118040 & 30 \\
\hline $2017 / 3 / 1$ & Landsat- 8 OLI & 118040 & 15 \\
\hline $2000 / 4 / 10$ & Landsat-5 TM & \multirow{2}{*}{119037} & 30 \\
\hline $2017 / 3 / 8$ & Landsat-8 OLI & & 15 \\
\hline $2000 / 6 / 13$ & & & \\
\hline $2000 / 7 / 22$ & Landsat-5 TM & \multirow{3}{*}{119038} & 30 \\
\hline $2000 / 9 / 17$ & & & \\
\hline $2017 / 3 / 8$ & Landsat-8 OLI & & 15 \\
\hline $2000 / 6 / 13$ & Landsat-5 TM & \multirow{3}{*}{119039} & 30 \\
\hline 2000/9/17 & Lantusat-s 1N & & 30 \\
\hline $\begin{array}{l}2017 / 5 / 11 \\
2017 / 11 / 3\end{array}$ & Landsat- 8 OLI & & 15 \\
\hline $2000 / 5 / 12$ & Landsat-5 TM & \multirow{2}{*}{119040} & 30 \\
\hline $2017 / 5 / 27$ & Landsat-8 OLI & & 15 \\
\hline $2000 / 10 / 8$ & Landsat-5 TM & \multirow{2}{*}{120037} & 30 \\
\hline $2017 / 5 / 18$ & Landsat- 8 OLI & & 15 \\
\hline $2000 / 10 / 8$ & Landsat-5 TM & \multirow{2}{*}{120038} & 30 \\
\hline $2017 / 5 / 18$ & Landsat-8 OLI & & 15 \\
\hline $2000 / 5 / 3$ & Landsat-5 TM & \multirow{2}{*}{120039} & 30 \\
\hline $2017 / 5 / 18$ & Landsat- 8 OLI & & 15 \\
\hline $2000 / 4 / 17$ & Landsat-5 TM & \multirow{2}{*}{120040} & 30 \\
\hline $2017 / 5 / 18$ & Landsat-8 OLI & & 15 \\
\hline
\end{tabular}

coordinate system using the Universal Transverse Mercator (UTM) projection.

2.2.3. Ground Observation Data. The remote sensing images selected for this study were obtained during the period of March to November for the years 2000 and 2017. To facilitate accurate visual interpretation of the images, more than 1500 reference ground objects, including 500 surface quadrats measuring $500 \times 500 \mathrm{~m}$, were randomly selected in the study area using a Trimble GEO-XT6000 GPS, with their latitudes and longitudes identified.

\subsection{Methods}

2.3.1. Data Preprocessing. Data preprocessing began with atmospheric correction on selected remote sensing images using the FLAASH module in ENVI 5.1 software. Second, geometric corrections were performed on the remote sensing images from 2017 using the latitude and longitude of reference ground objects as ground control point data, with the error held below 0.5 pixels. Next, geometric corrections were performed on the remote sensing images from 2000, using the geometrically corrected 2017 images as the reference. All the geometrically corrected images were then presented in the WGS84 coordinate system using the UTM projection. Finally, all the remote sensing images were tailored using the latest vector boundaries of the cities covered in this study.

2.3.2. Interpretation. Land cover in the study area was classified into one of the following six categories: farmland, forest, grassland, water bodies (including artificial water bodies), construction land, and unused land (including native vegetation and barren land). The classification was made by referencing GB/T21010-2017 Current Land Use Classification, issued by the General Administration of Quality Supervision, Inspection, and Quarantine of the People's Republic of China, and noting the characteristics of land use in the study area. The mean values, standard deviations, and correlation coefficients of the images were quantitatively analyzed by frequency band, using the Optimum Index Factor (OIF) method proposed by Lu et al. [34]. Next, the information content of various frequency band combinations was computed. The resulting OIF values were arranged sequentially from high to low. The red, near-infrared, and short-wave infrared bands (corresponding to bands 3, 4, and 5 and 4, 5, and 6 of Landsat-5 TM and Landsat-8 OLI, respectively) were selected as the preferred bands in correspondence to the purpose of the study, the particular situation of the study area, and the characteristics of the spectral-reflectance of different ground objects in the frequency bands of the images. Next, after repeated trials, the red, near-infrared, and short-wave infrared bands were 
rendered in blue, red, and green colors, respectively, to transform the data into quasicolor data. The resulting data showed strong color contrast for different ground objects and had rich color gradation, thereby facilitating manual data interpretation. Finally, the land uses of the study area in 2000 and 2017 were classified using the visual interpretation method, that is, the interpretation of the remote sensing images based on their spectral characteristics, geoscience patterns, and expertise as well as the brightness, color tone, texture, spatial relationship, and phase of image pixels, with the results presented in Figure 2.

2.3.3. Accuracy Evaluation. The confusion matrix method is now the most widely applied method for evaluating the classification accuracy of remote sensing images [35]. This method operates by comparing classification results and field observations using an $n \times n$ matrix (where $n$ is the number of classifications), with the elements in the matrix representing the number of pixels to be verified [36]. Research shows that the number of points for verifying the classification accuracy of a single class should be no less than 75 [37]. In the land use classification of this study, 200 points were randomly selected for each class of ground objects. Confusion matrices were established by comparing the classification results of these reference points at different time points with the corresponding field investigation results and high-resolution remote sensing data from Google Earth (including QuickBird, IKONOS, and SPOT5 satellites). Producer's accuracy, user's accuracy, overall accuracy, and Kappa coefficient were used to measure the land use classification accuracy, calculated as

$$
\begin{aligned}
P_{P A} & =\frac{K_{j j}}{K_{+j}}, \\
P_{U A} & =\frac{K_{i i}}{K_{i+}}, \\
P_{O A} & =\frac{\sum_{i=1}^{n} K_{i i}}{T}, \\
K & =\frac{T \sum_{i=1}^{n} K_{i i}-\sum_{i, j=1}^{n}\left(K_{i+} K_{+j}\right)}{T^{2}-\sum_{i, j=1}^{n}\left(K_{i+} K_{+j}\right)},
\end{aligned}
$$

where $P_{P A}$ is the producer's accuracy, $P_{U A}$ is the user's accuracy, $P_{O A}$ is the overall accuracy, $K$ is the Kappa coefficient, $n$ is the number of columns in the confusion matrix (number of classifications), $K_{i i}$ is the number of pixels in the matrix at the intersection of the $i$ th row and the $i$ th column (the number of correct classification), $K_{i+}$ and $K_{+j}$ are the total number of pixels in the $i$ th row and the $i$ th column, respectively, and $T$ is the total number of pixels used for the accuracy evaluation.

\subsection{Data Analysis}

2.4.1. Temporal Analysis. Transition matrix-based analytical results can intuitively reflect transitions between different types of ground objects during two adjacent periods [38, 39].
To analyze temporal changes of land use in the study area and to identify inherent driving factors of urban expansion and pattern of land use changes, the transition matrix method was combined with the overlay analysis function in ArcGIS 9.3 software to compute transition matrices of land use. These computational results were used to analyze the land use changes in the cities covered in the study during the period 2000-2017.

2.4.2. Spatial Analysis. To analyze the spatial differentiation and morphological evolution of urban land expansion in the Yangtze River Delta over the last 20 years, the dimension and intensity of land expansion in the region were analyzed by combining DEM elevation data, the expansion intensity index, and the equal-fan analysis method.

The expansion intensity index is the ratio of the area of urban land expansion to the total land area in a spatial unit in the study period. This index normalizes the annual mean expansion rate based on the land area in a spatial unit, thereby enabling comparative analysis. The expansion intensity index-an indicator of urban expansion status-enables a comparison between different geographical areas of a city in terms of the intensity, rate, and trend of land use expansion. The index is computed using the following equation $[40,41]$ :

$$
U_{i}=\frac{U_{a}-U_{b}}{T \times U_{c}} \times 100
$$

where $U_{i}$ is the expansion intensity in the $i$ th spatial unit, $U_{a}$ is the area of the urban land in the $i$ th spatial unit in period $a$, $U_{b}$ is the area of the urban land in the ith spatial unit in period $b, U_{c}$ is the total land area of the $i$ th spatial unit, and $T$ is the time span from period $a$ to period $b$ in the unit of year.

The equal-fan analysis operates by mapping a study area into a circle and dividing the circle into equal fans. The land use classifications in different periods are then plotted onto equal fans for overlay analysis, and the expansion intensities in different aspects are computed to describe the spatial differentiation in land classification. The center of the circle is usually the central business district (CBD) of a city $[42,43]$, with the radius of the circle determined based on the criteria that the circle can cover the entire city. In this study, each of the cities considered was divided into 16 equal fans (where the angle of each fan is $22.5^{\circ}$ ), with the division starting in the north. Urban land expansion intensity indices in the different fans in various periods were then computed. The computational results were then combined with the DEM elevation data to analyze the differentiation in urban spatial expansion intensity.

\section{Results}

3.1. Accuracy Evaluation. The accuracy of land use classifications for the Yangtze River Delta in 2000 and 2017 was evaluated by establishing confusion matrices and computing the producer's accuracy, user's accuracy, overall accuracy, and Kappa coefficient. Table 2 shows that the overall accuracies of the classifications in 2000 and 2017 were higher 


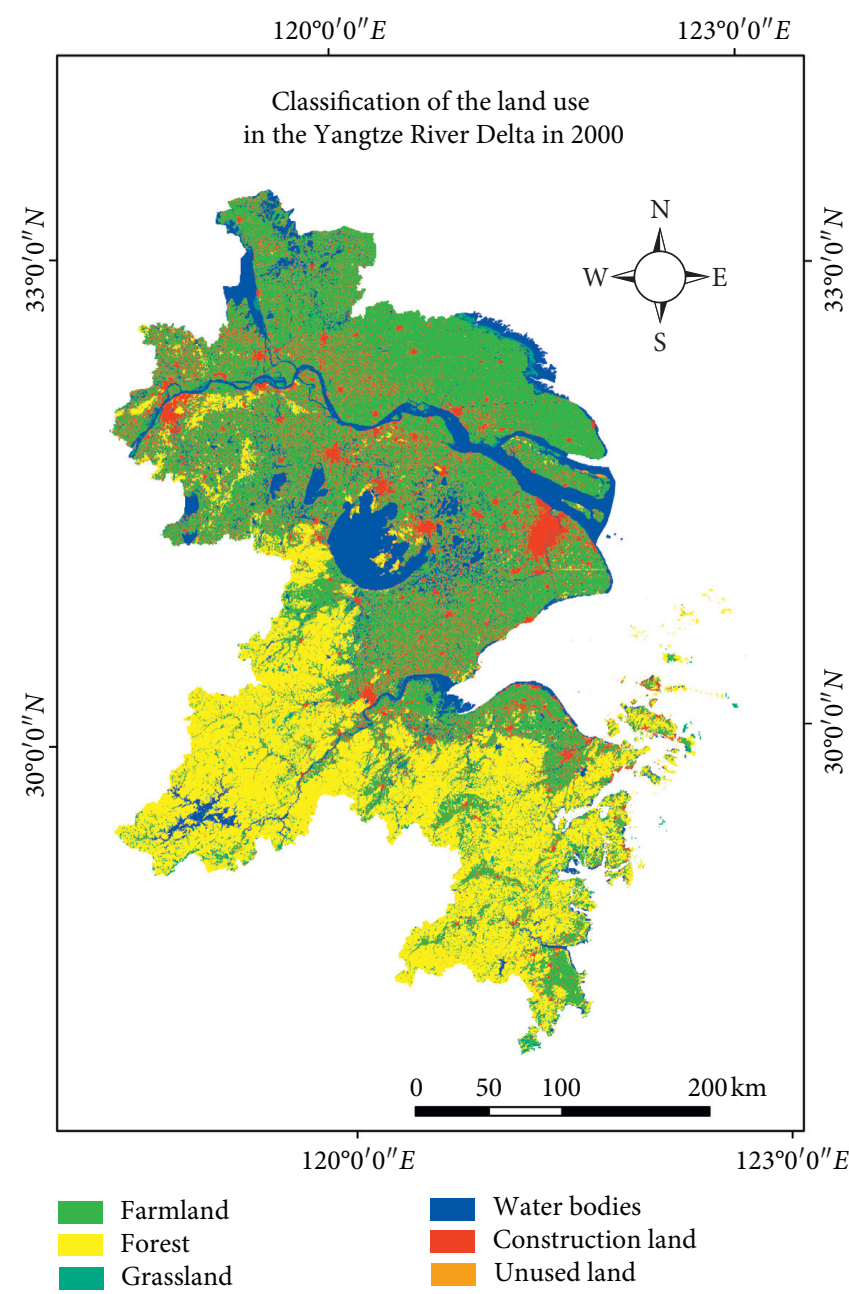

(a)

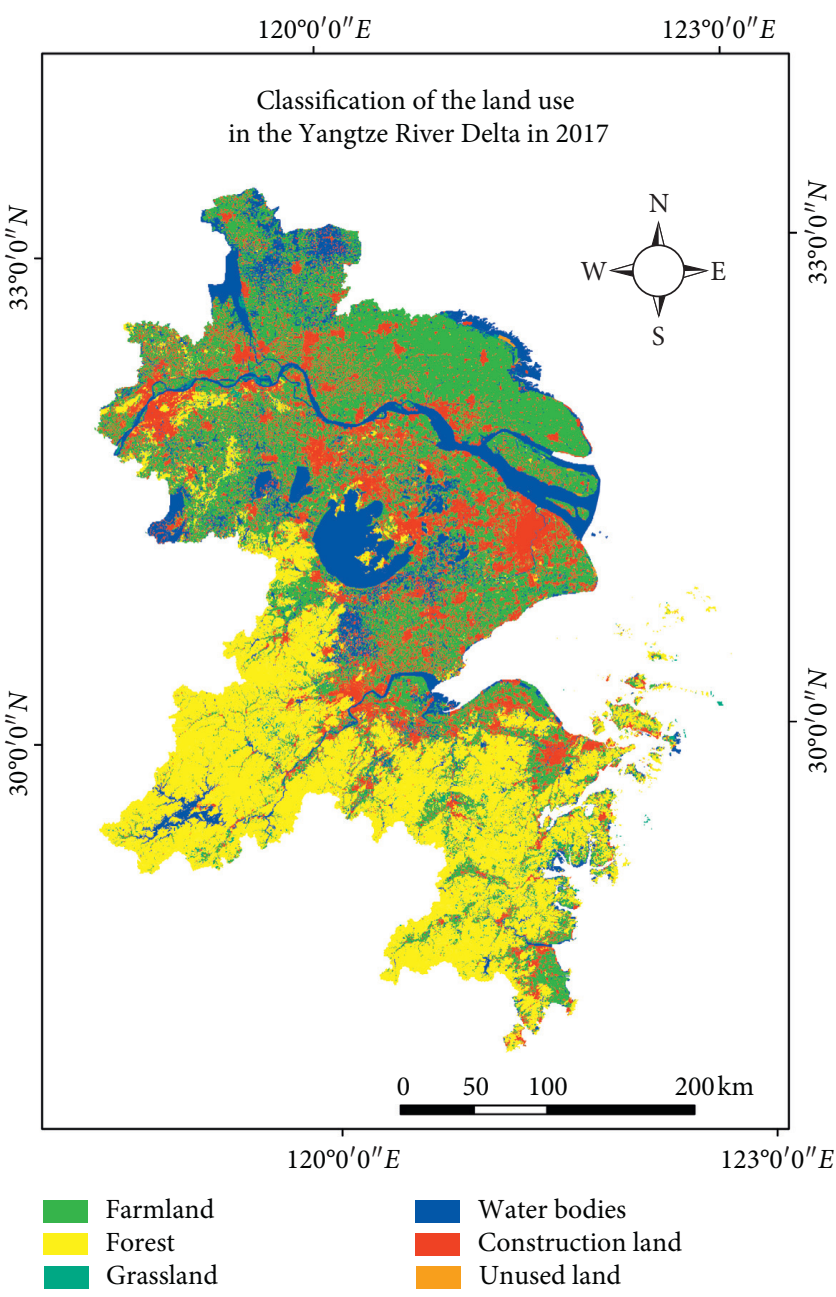

(b)

Figure 2: Classification of land use in the Yangtze River Delta in (a) 2000 and (b) 2017.

than $90 \%$, and the Kappa coefficients were greater than 0.90 . This confirms that the land use classifications were sufficiently accurate for this study. However, all accuracy indicators showed that the land use classification in 2017 was more accurate than in 2000, which is likely because the ground resolution of the Landsat- 8 OLI data used for the 2017 classification was higher than that of the Landsat-5 TM data used for the 2000 classification; this suggests, to a certain extent, that a higher spatial resolution leads to a more accurate visual interpretation. Moreover, the producer's accuracies and user's accuracies for the construction land classifications in 2000 and 2017 were higher than 93\%.

3.2. Temporal Changes in Urbanization. Among the six classifications of land use, a noticeable reduction of farmland and grassland occurred from 2000 to 2017. More specifically, farmland was reduced by approximately $1.11 \times 10^{6} \mathrm{hm}^{2}$, accounting for $9.92 \%$ of the total land, whereas the grassland accounted for less than $1 \%$ of the total land after its reduction. Forest, water bodies, construction land, and unused land increased in area during the study period, with the largest increase occurring for construction land which expanded by approximately $8.57 \times 10^{5} \mathrm{hm}^{2}$, equivalent to an increase of $7.61 \%$ of the total land. In contrast, forest, water bodies, and unused land increased only slightly, together accounting for approximately $2 \%$ of the total land (Figure 3 ). The area transition matrix analysis showed that construction land represented the largest transition in the 17 -year period. The area of farmland converted into construction land was approximately $8.91 \times 10^{5} \mathrm{hm}^{2}$ (Table 3), accounting for $47.66 \%$ of the total construction land in 2017.

Regarding the increase in the ratio of the construction land to the administrative areas (Figure 4), the cities covered in the study experienced different rates of urban spatial expansion. More specifically, Shanghai and Suzhou experienced the biggest increase (higher than 13\%), with the increase of Suzhou higher than that of Shanghai; Jiaxing and Wuxi experienced increases of approximately 10\%; Nanjing, Changzhou, and Taizhou (Jiangsu) of $8-9 \%$; Ningbo, Huzhou, Yangzhou, and Nantong of 6-8\%; and Zhenjiang, Shaoxing, Zhoushan, Hangzhou, and Taizhou (Zhejiang) of $4-6 \%$. 
TABLE 2: Classification accuracy evaluation results.

\begin{tabular}{|c|c|c|c|c|c|c|c|c|c|}
\hline Year & $\begin{array}{l}\text { Classification data } \\
\text { Verification data }\end{array}$ & Farmland & Forest & Grassland & $\begin{array}{l}\text { Water } \\
\text { bodies }\end{array}$ & $\begin{array}{l}\text { Construction } \\
\text { land }\end{array}$ & $\begin{array}{l}\text { Unused } \\
\text { land }\end{array}$ & Total & $\begin{array}{c}\text { Producer's } \\
\text { accuracy } \\
(\%)\end{array}$ \\
\hline \multirow{8}{*}{2000} & Farmland & 181 & 6 & 9 & 1 & 3 & 4 & 204 & 88.73 \\
\hline & Forest & 5 & 182 & 5 & 0 & 2 & 3 & 197 & 92.39 \\
\hline & Grassland & 6 & 6 & 180 & 2 & 2 & 4 & 200 & 90.00 \\
\hline & Water bodies & 1 & 0 & 1 & 190 & 4 & 4 & 200 & 95.00 \\
\hline & Construction land & 2 & 3 & 2 & 4 & 186 & 2 & 199 & 93.47 \\
\hline & Unused land & 5 & 3 & 3 & 3 & 3 & 183 & 200 & 91.50 \\
\hline & Total & 200 & 200 & 200 & 200 & 200 & 200 & 1200 & \\
\hline & $\begin{array}{c}\text { User's accuracy } \\
(\%)\end{array}$ & 90.50 & 91.00 & 90.00 & 95.00 & 93.00 & 91.50 & & \\
\hline \multicolumn{10}{|c|}{ Overall accuracy $=91.83 \%$; Kappa coefficient $=0.90$} \\
\hline \multirow{8}{*}{2017} & Farmland & 191 & 2 & 4 & 1 & 1 & 3 & 202 & 94.55 \\
\hline & Forest & 3 & 191 & 3 & 0 & 0 & 1 & 198 & 96.46 \\
\hline & Grassland & 2 & 3 & 189 & 0 & 1 & 2 & 197 & 95.94 \\
\hline & Water bodies & 0 & 0 & 0 & 195 & 3 & 2 & 200 & 97.50 \\
\hline & Construction land & 1 & 1 & 2 & 3 & 192 & 2 & 201 & 95.52 \\
\hline & Unused land & 3 & 3 & 2 & 1 & 3 & 190 & 202 & 94.06 \\
\hline & Total & 200 & 200 & 200 & 200 & 200 & 200 & 1200 & \\
\hline & $\begin{array}{c}\text { User's accuracy } \\
(\%)\end{array}$ & 95.50 & 95.50 & 94.50 & 97.50 & 96.00 & 95.00 & & \\
\hline & & Overall a & $c y=9$ & $\%$; Карра & ficient & & & & \\
\hline
\end{tabular}

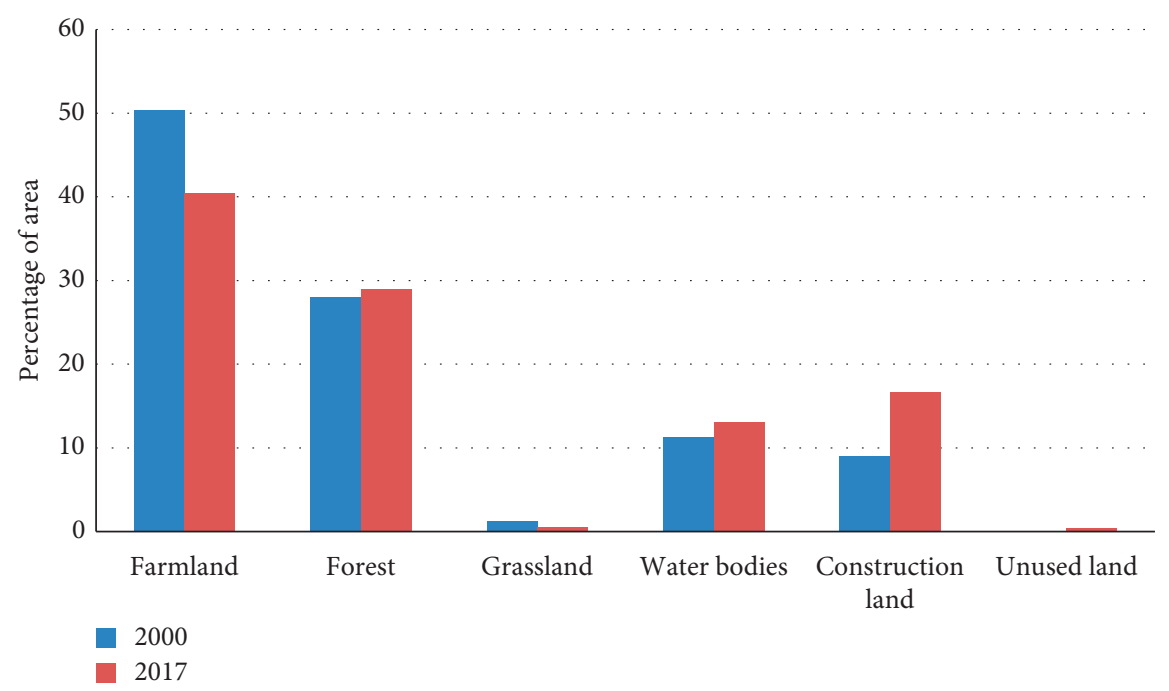

Figure 3: Changes (\%) in the different classifications of land use from 2000 to 2017.

TABle 3: Transition matrix of the land use transitions $\left(\mathrm{hm}^{2}\right)$ in the Yangtze River Delta from 2000 to 2017.

\begin{tabular}{|c|c|c|c|c|c|c|c|}
\hline \multirow[b]{2}{*}{2000} & \multicolumn{7}{|c|}{2017} \\
\hline & Farmland & Forest & Grassland & Water bodies & Construction land & Unused land & Total \\
\hline Farmland & 4327710 & 136653 & 3708 & 294997 & 891980 & 22339 & 5677387 \\
\hline Forest & 44518 & 3049272 & 2639 & 16808 & 37918 & 7299 & 3158454 \\
\hline Grassland & 5525 & 67091 & 48279 & 17019 & 5946 & 1730 & 145591 \\
\hline Water bodies & 82243 & 5721 & 2759 & 1122505 & 53019 & 6594 & 1272841 \\
\hline Construction land & 98675 & 8783 & 835 & 16196 & 882330 & 6527 & 1013347 \\
\hline Unused land & 1081 & 458 & 0 & 540 & 480 & 1894 & 4452 \\
\hline Total & 4559752 & 3267977 & 58220 & 1468066 & 1871672 & 46384 & 11272071 \\
\hline
\end{tabular}




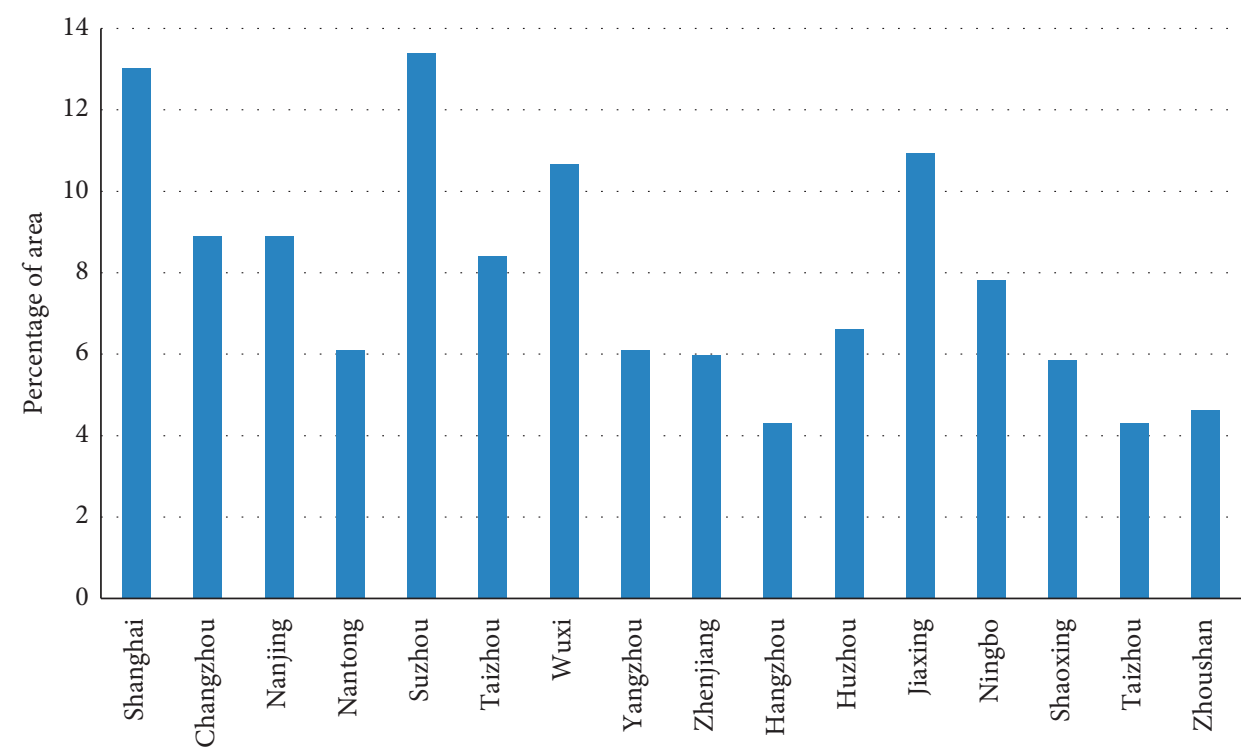

Figure 4: Increases (\%) in construction land in the Yangtze River Delta by city.

3.3. Spatial Changes of Urbanization. Expansion intensity indices for the municipalities identified above (Figure 1) were computed using an equal-fan analysis. The computational results for growth between 2000 and 2017 were then plotted as radar charts, as shown in Figure 5.

Shanghai experienced very rapid expansion in the SWW-W-NWW directions and rapid expansion in the NEE-SEE and SSE directions (Figure 5(a)). This is attributed to the accelerated development of the Hongqiao transportation hub in the west and the Pudong New Area and the Shanghai Port in the east.

Construction of the Xianlin University Town, the Qilin Science and Technology Park in the east, and the Jiangbei New District in the north contributed significantly to expansion in Nanjing (Figure 5(b)). These new constructions resulted in a significant increase in growth in the NE-NEE direction, but less rapid development in the SEE, SWW, and NW directions.

Zhenjiang underwent considerable growth in the NEE-E and SWW directions, together with noticeable expansion in the SE and SSW directions (Figure 5(c)). In the Zhenjiang Economic and Technological Development Zone, located in the eastern part of the city, a high-quality coated paper manufacturing base (the largest in the world), an engineering plastic particle base (the most extensive in China), an automobile engine cylinder block manufacturing base (the most substantial in China), and a controllable propeller manufacturing base were recently constructed. Located at the intersection of the Shanghai and Nanjing metropolitan areas, the Zhenjiang High-Tech Zone in the west of the city is included in the core area of the Nanjing-ZhenjiangYangzhou Integrated Strategy Initiative and is one of nine National High-Tech Zones in the southern Jiangsu National Innovation Demonstration Zone. The Zhenjiang Science and Technology Town, located in the southern part of the city, was constructed in 2016; therefore, the expansion intensity in this direction was slightly lower.
The municipality of Yangzhou (Figure 5(d)) saw significant development in the SSE direction together with notable expansion in the SE, S, SSW, and SW directions. The National Economic Development Zone, located in the southern part of the city, boasts the geographical advantage of being adjacent to seas and rivers, an investment environment with comprehensive support facilities, and an industrial base with unique characteristics. Following the construction of an integrated transportation hub in the eastern part of the city in 2016, the focus of the urban expansion has gradually shifted to the SE direction.

Taizhou (Jiangsu) City experienced very rapid expansion in the S-SSW and SWW directions and extensive growth to the NNE and NEE (Figure 5(e)). Construction of the Taizhou Medical New \& High-tech Industrial Development Zone, the Taizhou Binjiang Industrial Park, and the Riverside Economic Development Zone has significantly driven urban expansion in this area.

Considerable development took place in Nantong (Figure 5(f)), primarily in the SE direction, with additional heightened growth in the SWW. Due to the strong economic attraction, Shanghai has served as a driving force of the urban development of Nantong. Since the Tongzhou municipality was reorganized as a district in 2009, urban development has gradually shifted from the south (Chongchuan and Gangzha Districts) to the southeast.

In Changzhou, marked expansion in the N-NNE and E-SEE directions and development to a lesser degree in the SSE direction were observed (Figure 5(g)). This is mainly because the Changzhou National High-tech Development Zone is in the north of the city and construction projects for equipment manufacturing, new chemical materials, and port logistics have been implemented in the Riverside Economic Development Zone since 2006. Located in the eastern part of the city, the Changzhou Economic Zone displays the most rapid development. 


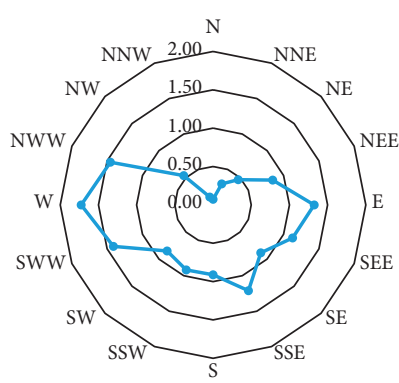

(a)

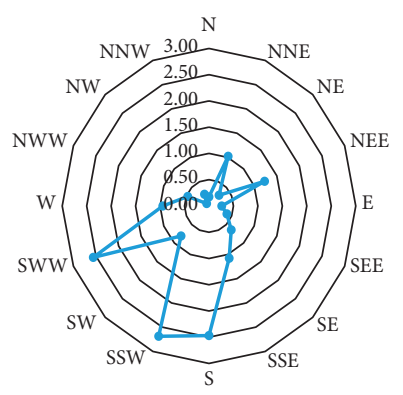

(e)

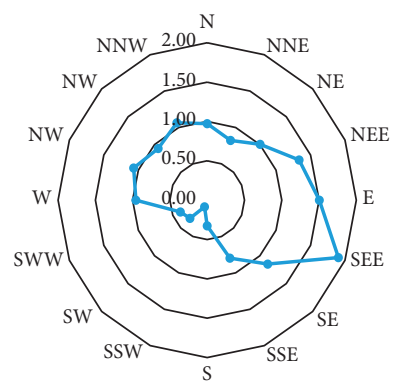

(i)

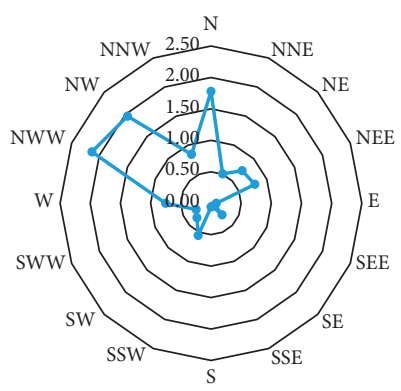

(m)

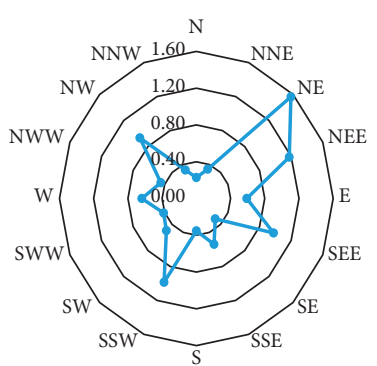

(b)

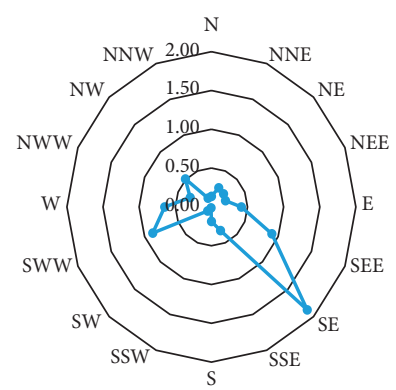

(f)

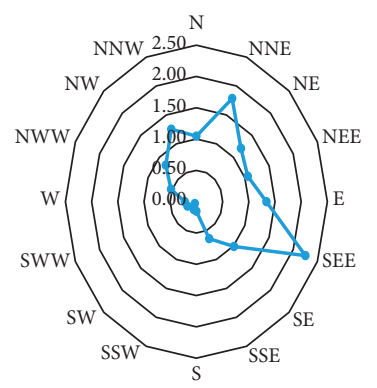

(j)

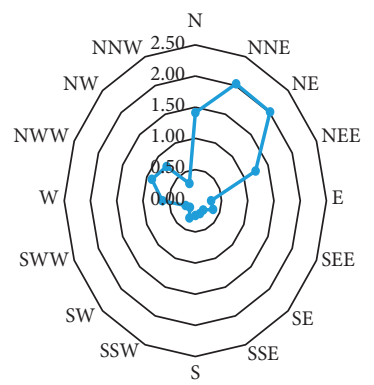

(n)

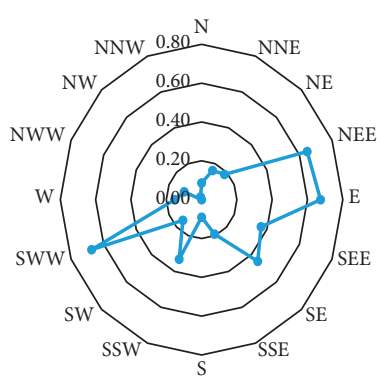

(c)

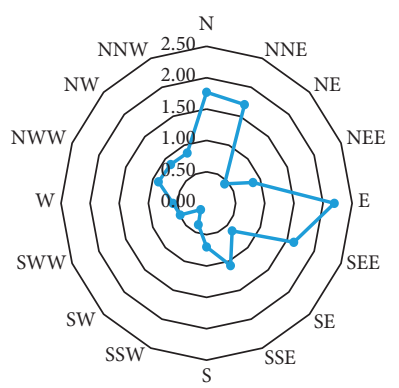

(g)

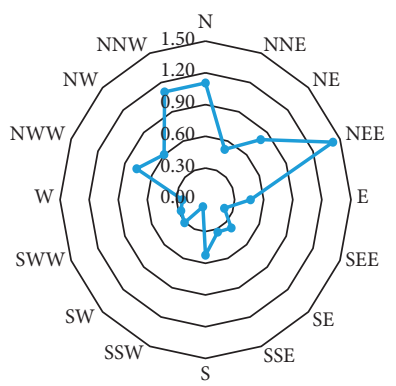

(k)

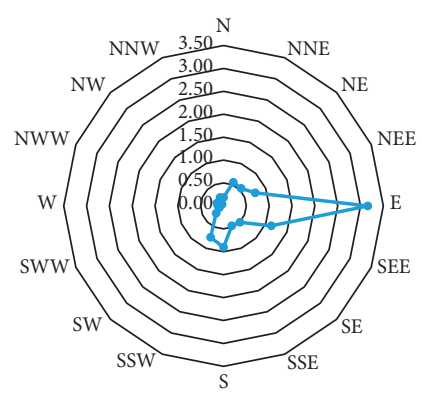

(o)

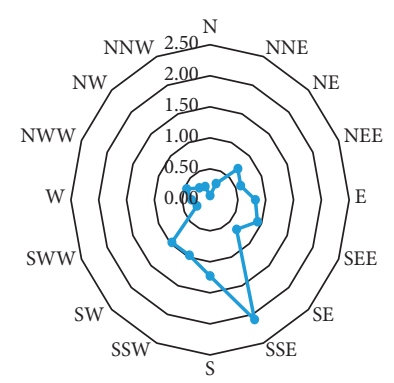

(d)

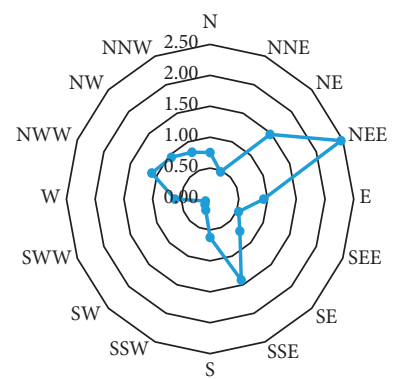

(h)

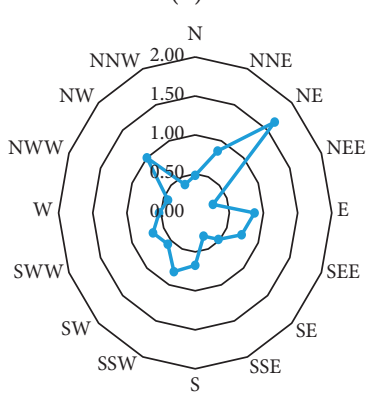

(1)

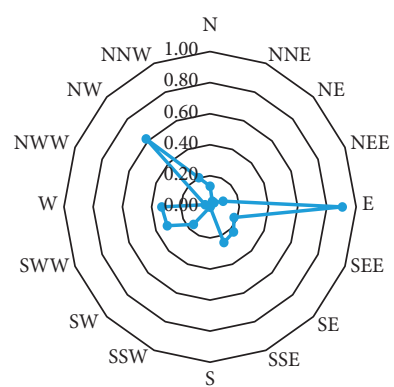

(p)

Figure 5: Spatial expansion directions of cities covered in the study during the period 2000-2017. The numbers in the (a) (p) were calculated by equation (2), representing the expansion intensity in the spatial direction. (a) Shanghai. (b) Nanjing. (c) Zhenjing. (d) Yangzhou. (e) Taizhou (Jiangsu). (f) Nantong. (g) Changzhou. (h) Suzhou. (i) Wuxi. (j) Hangzhou. (k) Huzhou. (l) Jiaxing. (m) Shaoxing. (n) Ningbo. (o) Taizhou. (p) Zhoushan.

Suzhou (Figure 5(h)) experienced very rapid expansion in the NEE direction and evident growth in the SSE and NWW direction. Construction projects in the Suzhou Industrial Park, the Wujiang Lakeside New Town, and the Suzhou National Hi-Tech District contributed to the significant expansion in the easterly direction.

Wuxi experienced noticeable expansion in the NEE-ESEE-SE-SSE direction (Figure 5(i)). Construction of the
Xishan District in the east and the attraction of Shanghai and Suzhou contributed to significant expansion in the southeast direction.

The city of Hangzhou (Figure 5(j)) experienced very rapid development in the SEE direction and rapid growth in the NNE and NNW directions. The urban development of Hangzhou to the west is constrained by the western Zhejiang hilly area. The east side of Hangzhou is located on the 


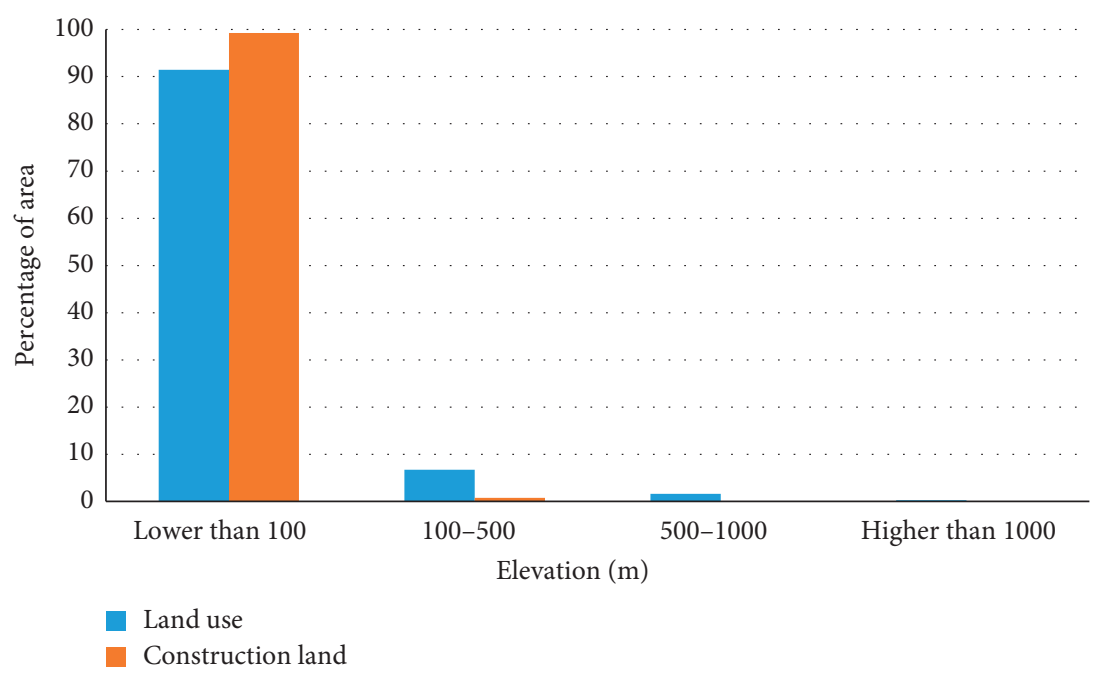

Figure 6: Land use changes (\%) by elevation.

Northern Zhejiang Plain and has traditionally been a manufacturing hub. As such, Hangzhou experienced significant expansion to the east, particularly after the planning and construction of the Jiangdong New District.

Huzhou experienced marked expansion in the NEE and NNW-N directions and rapid increases in growth in the NWW and S directions (Figure 5(k)). The construction of the Taihu New Town contributed to significant expansion in the north and east.

In Jiaxing, well-defined expansion occurred in the NE direction (Figure 5(l)), simultaneously with minor expansion to the E, SSW, and NW. Jiaxing adopts integration into Shanghai-in particular, integration with the Jinshan and Songjiang Districts of Shanghai-as its core strategy of urban development. Therefore, Jiaxing exhibited significant growth to the east and more significantly the northeast.

Shaoxing experienced very rapid growth in the $\mathrm{N}$ and NWW-NW directions and notable expansion in the NEE and SSW directions (Figure 5(m)). Expansion to the NW-N is a direct result of the construction projects implemented in recent years, including a textile and small motor center, an energy-saving photoelectricity center, and a biological brewing industry.

Ningbo experienced marked development to the N-NNE-NE-NEE (Figure 5(n)) and to a lesser extent in the NWW direction. The Ningbo Hangzhou Bay New Zone-a National Economic and Technological Development Zone-is in the north of Ningbo. In addition, large petroleum, chemical, and steel enterprises are constructed in the Beilun and Zhenhai Districts in the eastern part of the city.

In the city of Taizhou (Zhejiang), significant expansion took place in the E direction, owing to port construction. In addition, minor growth was noted to the south (Figure 5(o)).

Zhoushan-a city surrounded by sea-experienced very rapid development in the $\mathrm{E}$ and NW directions and rapid expansion in the SSE and SWW-W directions (Figure 5(p)). This growth is attributed to the construction of the Zhoushan Port in the east and the Jintang Bridge that connects Ningbo in the west.
The land use classification and DEM elevation data of the study area were overlain to perform an expansion classification analysis in order to understand how elevation affects land use and expansion. The results show that more than $90 \%$ of land use changes occurred in areas with an elevation of less than $100 \mathrm{~m}, 99 \%$ of the construction land expansions occurred in areas with an elevation of less than $100 \mathrm{~m}$, and land use changes, particularly changes in construction land, decreased with an increase in elevation (Figure 6).

\section{Discussion}

The most drastic land use changes from 2000 to 2017 resulted from farmland and construction, with the overall pattern of land use change being the conversion of the former to the latter. The assessment of spatial changes in urbanization in the 15 cities (excluding Shanghai) demonstrated an increasing rate of urbanization that is higher than $6 \%$ in 7 cities which are located within Jiangsu Province. This indicates that the overall urbanization rate of Jiangsu Province exceeds that of Zhejiang Province (Figure 1). In addition, cities in the Yangtze River Delta megalopolis with the exclusion of Shanghai, a municipality directly under the central government, Nanjing, capital of Jiangsu Province, and Hangzhou, capital of Zhejiang Province, have the following urban spatial expansion characteristics: (1) expansion towards a municipality that is directly administrated by the central government or the provincial capital, for example, Suzhou, Wuxi, Changzhou, and Nantong expanding towards Shanghai or Huzhou and Jiaxing and Shaoxing expanding towards Hangzhou; and (2) expansion towards major port hubs and industrial platforms along the Yangtze River or the coast, for example, Yangzhou, Taizhou (Jiangsu), and Zhenjiang expanding along the Yangtze River and Ningbo, Taizhou (Zhejiang), and Zhoushan expanding towards sea ports. This indicates that urban expansion is influenced by geographical factors to a certain degree, in addition to the influence of policy factors. 
Notably, the present study has certain limitations. First, it spanned a long period, but higher temporal resolution data are needed to further investigate urban expansion during this period. In addition, only the key factors influencing urban spatial expansion were considered, yet the addition of socioeconomic indicators would help explain the demand factor of urban land expansion. For future studies, multiplesource remote sensing data with a higher resolution should be used to obtain a more accurate classification of land use, and longer periods should be covered to carry out an indepth investigation of the characteristics of urban expansion by stage. Economic, social, and ecological factors in addition to the topographical, geographical, and policy factors should be included and additional analysis methods and measurement indicators, such as compactness, fractal index, and landscape index, should be employed to comprehensively analyze the urban expansion characteristics and pattern of the study area.

\section{Conclusions}

In this study, the land use of 16 cities in the Yangtze River Delta in 2000 and 2017 was classified by carrying out a visual interpretation of 31 images from the Landsat series satellites. Land use classification data were then combined with DEM elevation data to analyze the urban spatial expansion pattern of the cities by employing a transition matrix, an expansion intensity index, and an equal-fan analysis method. We arrived at the following conclusions: (1) land use change in the core area of the Yangtze River Delta from 2000 to 2017 significantly increased and exhibited characteristics of rapid urban expansion; (2) the southern and northern parts of the core area experienced different urban spatial expansions, with the scale and rate of urban expansion in the cities along the Yangtze River and the northern coast in Jiangsu Province higher than those of cities in Zhejiang Province to the south; (3) cities expanded towards megacities or hubs along the Yangtze River or the coast, indicating that urban expansion was also influenced by preferential policy and urban development planning factors in addition to the size of neighboring cities and geographic conditions (i.e., proximity to seas or large rivers); (4) urban expansion is significantly constrained by elevation, whereby cities with lower elevation or flat terrain were subject to enhanced urban spatial expansion and development relative to cities located in hilly or mountainous areas.

The method demonstrated is potentially applicable to other megalopolises such as the Northeastern Corridor region on the United States coast, the Great Lakes in North America, the Pacific coastal area of Japan, London in the UK, and northwestern Europe. The methods employed here will aid planners to understand the spatiotemporal factors driving urban expansion, facilitate more reasonable integration and utilization of the limited land resources, and provide valuable input for scientific long-term development planning of megalopolises.

\section{Data Availability}

Data are available upon request.

\section{Conflicts of Interest}

The authors declare that there are no conflicts of interest regarding the publication of this paper.

\section{Acknowledgments}

The authors acknowledge USGS for providing Landsat data, and the ASTER GDEM V2 data were provided by Geospatial Data Cloud site, Computer Network Information Center, Chinese Academy of Sciences. This work was supported by the National Natural Science Foundation of China, under Grant no. 41871119, the Jiangsu Agricultural Science and Technology Innovation Fund, under Grant no. CX-18-3044, and the Natural Resource Science and Technology Foundation of Jiangsu Province, under Grant no. 2020009.

\section{References}

[1] National Bureau of Statistics of the People's Republic of China, China Statistical Yearbook 2019, China Statistics Press, Beijing, China, 2019.

[2] L. Wang, C. C. Li, Q. Ying et al., "China's urban expansion from 1990 to 2010 determined with satellite remote sensing," Chinese Science Bulletin, vol. 57, pp. 1388-1399, 2012, in Chinese, with English abstract.

[3] K. T. Jackson, Crabgrass Frontier: The Suburbanization of the United States, p. 12, Oxford University Press, New York, NY, USA, 1985.

[4] R. Camagni, M. C. Gibelli, and P. Rigamonti, "Urban mobility and urban form: the social and environmental costs of different patterns of urban expansion," Ecological Economics, vol. 40, no. 2, pp. 199-216, 2002.

[5] D. Guanglong, X. Erqi, and Z. Hongqi, "Urban expansion and spatiotemporal relationships with driving factors revealed by geographically weighted logistic regression," Journal of Resources and Ecology, vol. 8, no. 3, pp. 277-286, 2017.

[6] J. G. Masek, F. E. Lindsay, and S. N. Goward, "Dynamics of urban growth in the Washington DC metropolitan area, 1973-1996, from Landsat observations," International Journal of Remote Sensing, vol. 21, no. 18, pp. 3473-3486, 2000.

[7] W. Ji, J. Ma, R. W. Twibell, and K. Underhill, "Characterizing urban sprawl using multi-stage remote sensing images and landscape metrics," Computers, Environment and Urban Systems, vol. 30, no. 6, pp. 861-879, 2006.

[8] B. K. Terfa, N. Chen, D. Liu, X. Zhang, and D. Niyogi, “Urban Expansion in Ethiopia from 1987 to 2017: characteristics, spatial patterns, and driving forces," Sustainability, vol. 11, no. 10, p. 2973, 2019.

[9] U. Alganci, "Dynamic land cover mapping of urbanized cities with Landsat 8 multi-temporal images: comparative evaluation of classification algorithms and dimension reduction methods," ISPRS International Journal of Geo-Information, vol. 8, no. 3, p. 139, 2019.

[10] H. Moayedi, A. Jamali, M. B. A. Gibril, L. Kok Foong, and M. Bahiraei, "Evaluation of tree-base data mining algorithms in land used/land cover mapping in a semi-arid environment through Landsat 8 OLI image; Shiraz, Iran," Geomatics, Natural Hazards and Risk, vol. 11, no. 1, pp. 724-741, 2020.

[11] J. A. Gomez, J. E. Patino, J. C. Duque, and S. Passos, "Spatiotemporal modeling of urban growth using machine learning," Remote Sensing, vol. 12, p. 109, 2020. 
[12] H. M. Pham, Y. Yamaguchi, and T. Q. Bui, "A case study on the relation between city planning and urban growth using remote sensing and spatial metrics," Landscape and Urban Planning, vol. 100, no. 3, pp. 223-230, 2011.

[13] Q. Zhang and K. C. Seto, "Mapping urbanization dynamics at regional and global scales using multi-temporal DMSP/OLS nighttime light data," Remote Sensing of Environment, vol. 115, no. 9, pp. 2320-2329, 2011.

[14] J. Yang, J. Sun, H. Zhao, J. Xi, and X. Li, "Spatio-temporal differentiation of residential land for coastal town: a case study of Dalian Jinshitan," Chinese Geographical Science, vol. 26, no. 4, pp. 566-576, 2016.

[15] J. Peng, H. Lin, Y. Chen et al., "Spatiotemporal evolution of urban agglomerations in China during 2000-2012: a nighttime light approach," Landscape Ecology, vol. 35, no. 2, pp. 421-434, 2020.

[16] L. Wang, H. Anna, L. Zhang et al., "Spatial and temporal changes of arable land driven by urbanization and ecological restoration in China," Chinese Geographical Science, vol. 29, no. 5, pp. 809-819, 2019.

[17] Y. Zhao, K. Zhong, J. Xu, C. Sun, and Y. Wang, "Directional analysis of urban expansion based on sub-pixel and regional scale: a case study of main districts in Guangzhou, China," Chinese Geographical Science, vol. 29, no. 4, pp. 652-666, 2019.

[18] D. Ben, Z. Cao, X. Liu et al., "Changing connectivities of Chinese cities in the world city network, 2010-2016," Chinese Geographical Science, vol. 28, no. 2, pp. 183-201, 2018.

[19] S. Jin, J. Yang, E. Wang, and J. Liu, "The influence of highspeed rail on ice-snow tourism in northeastern China," Tourism Management, vol. 78, p. 104070, 2020.

[20] M. Anxin and L. Meng, "Sediment of Yangtze and urbanization of Shanghai monitoring by using remote sensing," Remote Sens. Inform.vol. 2, p. 12, 1990, in Chinese, with English abstract.

[21] F. Zuojiang, C. Jicheng, and L. Qi, "Urbanization monitoring by remote sensing and geography information system," Remote Sensing Information, vol. 3, pp. 12-16, 1997, in Chinese, with English abstract.

[22] X. Li, J. Fang, and S. Piao, "The comparison of spatial characteristics in urban landuse growth among the central and sub-cities in Shanghai Region," Geographical Research, vol. 22, pp. 769-779, 2003, in Chinese, with English abstract.

[23] R. H. Ma, C. L. Gu, Y. X. Pu, X. D. Ma, and Z. Zhu, "Urban spatial sprawl pattern and metrics in south of Jiangsu province along the Yangtze river," Acta Geographica Sinica, vol. 62, pp. 1011-1022, 2007, in Chinese, with English abstract.

[24] J. L. Gao, J. L. Chen, F. Yuan, Y. D. Wei, and W. Chen, "Patterns, functions and underlying mechanisms of urban land expansion in Nanjing," Geographical Research, vol. 33, pp. 1892-1907, 2014, in Chinese, with English abstract.

[25] D.-D. Zhang and L. Zhang, "Land cover change in the central region of the lower Yangtze River based on Landsat imagery and the Google earth engine: a case study in nanjing, China," Sensors, vol. 20, no. 7, p. 2091, 2020.

[26] J. Li, J. Xu, W. Li, and C. Liu, "Spatio-temporal characteristics of urbanization area growth in the Yangtze River Delta," Acta Geographica Sinica, vol. 62, pp. 437-447, 2007, in Chinese, with English abstract.

[27] L. Wang and X. Duan, "The expansion of urbanization area in Yangtze River Delta," Scientia Geographica Sinica, vol. 16, pp. 702-709, 2010, in Chinese, with English abstract.

[28] Q. Che, X. Duan, Y. Guo, L. Wang, and Y. Cao, "Urban spatial expansion process, pattern and mechanism in Yangtze River
Delta," Acta Geographica Sinica, vol. 66, pp. 446-456, 2011, in Chinese, with English abstract.

[29] C. P. Wang, H. W. Wang, C. M. Li, and R. C. Dong, "Analysis of the spatial expansion characteristics of major urban agglomerations in China using DMSP/OLS images," Acta Ecologica Sinica, vol. 32, pp. 942-954, 2012, in Chinese, with English abstract.

[30] X. Gao, H. Liu, Y. Zhang et al., "Spatio-temporal patterns of urban expansion in the Yangtze River Delta megalopolis from 1990 to 2010," Journal of Beijing Normal University (Natural Science), vol. 52, pp. 645-650, 2016, in Chinese, with English abstract.

[31] X. Xu and Y. Zhou, Urban Geography, Higher Education Press, Beijing, China, 1997.

[32] Jiangsu Provincial Bureau of Statistics, Jiangsu Statistical Yearbook 2017, China Statistics Press, Beijing, China, 2017.

[33] Zhejiang Provincial Bureau of Statistics, Zhejiang Statistical Yearbook 2017, China Statistics Press, Beijing, China, 2017.

[34] D. Lu, X. You, and S. Cui, "A study on the analysis of TM image information content and the extraction of characteristic information," Journal of Remote Sensing, vol. 6, no. 4, pp. 267-274, 1991, in Chinese, with English abstract.

[35] R. G. Congalton and K. Green, Assessing the Accuracy of Remotely Sensed Data: Principles and Practices, CRC Press, Boca Raton, FL, USA, 2nd edition, 2009.

[36] R. G. Congalton, "A review of assessing the accuracy of classifications of remotely sensed data," Remote Sensing of Environment, vol. 37, no. 1, pp. 35-46, 1991.

[37] J. Cohen, "Weighted kappa: nominal scale agreement provision for scaled disagreement or partial credit," Psychological Bulletin, vol. 70, no. 4, pp. 213-220, 1968.

[38] D. Xiao, Y. Zhao, Z. Sun, and G. Zhang, "Study on the variation of landscape pattern in the west suburbs of Shenyang," Chinese Journal of Applied Ecology, vol. 1, pp. 75-84, 1990, in Chinese, with English abstract.

[39] P. Shi, J. Chen, and Y. Pan, "Landuse change mechanism in Shenzhen city," Acta Geographica Sinica, vol. 55, pp. 151-160, 2000, in Chinese, with English abstract.

[40] W. Wang, J. Jin, Z. Xiao, and T. Shi, "Urban expansion and its driving forces based on remote sensed data and GIS: a case study of Hangzhou city from 1991 to 2008," Geographical Research, vol. 28, pp. 687-695, 2009, in Chinese, with English abstract.

[41] S. H. Liu, C. J. WU, and H. Q. Shen, "A GIS based model of urban land use growth in beijing," Acta Geographica Sinica, vol. 55, pp. 407-416, 2000, in Chinese, with English abstract.

[42] Z. Shang, X. Zhang, and X. Zhou, "Study on urban spatial expansion and external morphology evolution based on RS/ GIS: a case of Huai'an city," Economic Geography, vol. 32, pp. 64-70, 2012, in Chinese, with English abstract.

[43] S. Jiang and Y. Zhou, "The fractal urban form of Beijing and its practical significance," Geographical Research, vol. 25, pp. 204-212, 2006, in Chinese, with English abstract. 